\title{
DO CONTROLE JUDICIAL DA POLÍTICA PÚBLICA DE MOBILIDADE URBANA NO PARADIGMA SUSTENTÁVEL ${ }^{1}$
}

\section{THE JUDICIAL CONTROL OF THE PUBLIC POLICY URBAN MOBILITY IN SUSTAINABLE PARADIGM}

\author{
Magno Federici Gomes ${ }^{2}$ \\ Ariel Augusto Pinheiro dos Santos ${ }^{3}$
}

\section{Resumo}

O artigo trata do controle judicial da política pública na questão do itinerário das linhas de transporte público coletivo, tema de extrema relevância no debate brasileiro. Tal importância é reforçada pela Lei $\mathrm{n}^{\circ}$ 12.587/2009 (Lei de Mobilidade Urbana) e principalmente pela promulgação da Emenda Constitucional (EC) no 90/2015, que arrolou como direito social o transporte. Utilizou-se as linhas jurídico-sociológica e jurídico-interpretativa na pesquisa, uma vez que o fenômeno estudado ultrapassa o campo de estudo do direito. Aplicou-se, ainda, a técnica dedutiva na investigação. A conclusão foi a obrigatoriedade da observância das dimensões do desenvolvimento sustentável e dos princípios da Lei de Mobilidade Urbana, além da possibilidade de mudança de instância decisória da política pública.

Palavras-chave: Mobilidade urbana; Direito social ao transporte; Desenvolvimento sustentável; Ativismo judicial.

\begin{abstract}
The paper deals with the judicial control of public policy on the issue of the route of public transportation lines. The theme is extremely relevant in the Brazilian debate. The importance is reinforced by Act 12.587/2009 (Urban Mobility Act) and especially the enactment of Constitutional Amendment 90/2015, which enrolled the transportation as a social right. The legal and sociological line and the legal and interpretive line were used in the research, since the study phenomenon goes beyond the law field. The paper applied deductive technical. The conclusion was the obligation of compliance with the dimensions of sustainable development and the principles of Urban Mobility Act, plus the ability to shift decision-making body of public policy.
\end{abstract}

Keywords: Urban mobility; Social right to transport; Sustainable development; Judicial activism.

\footnotetext{
${ }^{1}$ Trabalho financiado pelo Edital no 05/2016 (Projeto no FIP 2016/11173-S2) do FIP/PUC, resultante dos Grupos de Pesquisas (CNPQ): Regulação Ambiental da Atividade Econômica Sustentável (REGA) e CEDIS (FCT-PT).

2 Pós-doutor em Direito Público e Educação pela Universidade Nova de Lisboa-Portugal. Pós-doutor em Direito Civil e Processual Civil. Professor do Mestrado Acadêmico em Direito Ambiental e Sustentabilidade na Escola Superior Dom Helder Câmara. Professor Adjunto da PUC Minas e Professor Titular licenciado da Faculdade de Direito Arnaldo Janssen. Integrante dos grupos de pesquisa: Regulação Ambiental da Atividade Econômica Sustentável (REGA)/CNPQ-BRA, Centro de Investigação \& Desenvolvimento sobre Direito e Sociedade (CEDIS)/FCT-PT e Núcleo de Estudos sobre Gestão de Políticas Públicas (NEGESP)/CNPQ-BRA. E-mail: federici@pucminas.br

${ }^{3}$ Mestre em Direito Ambiental e Desenvolvimento Sustentável pela Escola Superior Dom Helder Câmara. Mestrando em Políticas Públicas pela UFMG. E-mail: ariel5002@hotmail.com
} 


\section{INTRODUÇÃO}

O presente trabalho visa problematizar a possibilidade de se judicializar a tomada de decisão sobre a trajetória das linhas de transporte público quando não observarem as dimensões do desenvolvimento sustentável e os princípios da Lei de Mobilidade Urbana (Lei no 12.587/2009). O tema possui grande relevância na atualidade, tendo em vista o estado crítico do trânsito urbano brasileiro, sendo necessária uma política de transporte público eficiente, efetiva e eficaz, para reduzir os atuais problemas de tráfego das grandes cidades no país. A hipótese afirma que é direito do indivíduo, ou de uma coletividade, invocar o Poder Judiciário para a resolução de um problema relacionado ao trajeto das linhas de transporte coletivo. Portanto, caso o cidadão entenda que seus direitos foram desrespeitados no processo de elaboração do itinerário do transporte público, poderá recorrer a uma instância independente e imparcial, que no caso brasileiro é o Poder Judiciário.

O estudo baseará na premissa que a comunidade deve ser ouvida pelo administrador público na tomada de decisões sobre as linhas de ônibus ${ }^{4}$ e, caso ocorra a inobservância desse procedimento ou dos caracteres do desenvolvimento sustentável ou dos princípios da Lei de Mobilidade Urbana, caberá ao interessado aceder ao Poder Judiciário, tendo em vista o paradigma do Estado Democrático de Direito.

O desenvolvimento da pesquisa utilizou-se da linha jurídico-sociológica como linha teórico-metodológica, uma vez que analisar mobilidade urbana ultrapassa o campo de estudo do direito, sendo necessária a visita a outros ramos do conhecimento para uma resposta adequada do problema. Ademais, a investigação jurídico-interpretativa também foi empregada na pesquisa, em virtude da imprescindibilidade de decompor o problema para uma resolução mais informada.

Por sua vez, a técnica de raciocínio utilizada foi a dedutiva, já que é de suma importância estabelecer princípios gerais sobre a intervenção do Poder Judiciário nas políticas públicas, as dimensões do desenvolvimento sustentável e de forma mais específica os princípios da Lei de Mobilidade Urbana, para então verificar a pertinência da hipótese na resposta do problema apresentado.

O desenvolvimento do texto obedeceu à seguinte divisão: a primeira parte discute o direito fundamental social ao transporte, no qual será feita uma comparação com o direito à liberdade de locomoção, informando as diferenças entre os institutos. Também será debatida a

\footnotetext{
${ }^{4}$ Segundo os parâmetros de consensualização e concertação do ato administrativo.
} 
fundamentação legislativa para a introdução dessa prerrogativa no rol dos direitos sociais do art. 6o da Constituição da República de 1988 (CR/88). A segunda trará a polêmica sobre o controle judicial de políticas públicas, assunto que tem sido largamente debatido na doutrina e na jurisprudência. Uma rápida cognição sobre a questão informa a necessidade de compatibilização do princípio da separação dos poderes com a possibilidade de acesso à jurisdição, algo crucial na noção de Estado Democrático de Direito. Em função da grande abrangência do tema, será recortada uma fundamentação geral e assimilada a questão do transporte urbano de comunidades.

Após, tratar-se-á da noção de desenvolvimento sustentável. Será abordada a concepção clássica, que agrega caracteres econômicos, sociais e ambientais. Contudo, percebe-se que tal significado pode ser insuficiente para uma aplicação plena do termo. Dessa forma, levantar-se-á novas dimensões sobre o termo para uma cognição exauriente da questão de mobilidade urbana.

Nos próximos apartados tratar-se-á a participação do Poder Judiciário na política pública de transporte urbano coletivo e os caracteres que devem ser utilizados para a tomada de decisão pelo ator político. Em um primeiro momento esse ator político é o administrador público membro do Poder Executivo e, no segundo momento, após o ajuizamento de uma ação judicial, o próprio juiz.

\section{DIREITO FUNDAMENTAL SOCIAL AO TRANSPORTE}

A evolução dos direitos acompanha a construção do estado moderno (ZANIN, 2008, BONAVIDES, 2010). No momento em que se considerou uma ingerência abusiva do Estado nas relações particulares, especialmente a liberdade de locomoção e a propriedade, estabeleceu-se limites a esta atuação abusiva. Zanin (2008) ressalta o conteúdo da Carta Magna inglesa elaborada em 1215 (Magna Charta Libertatum), sob esses dois pilares: "entre outras garantias a Carta Magna previa: liberdade da Igreja da Inglaterra; restrições tributárias; proporcionalidade entre delito e sanção, devido processo legal, livre acesso à justiça; liberdade de locomoção" (ZANIN, 2008, p. 174). A restrição ao poder do monarca tributar é um modo de proteção da propriedade privada e a liberdade de locomoção foi coroada com o devido processo legal e outros instrumentos.

Nota-se que, inicialmente, a luta da sociedade frente ao Estado foi no sentido de liberdade, isto é, a atuação estatal deveria ter limites e não poderia sem uma justa causa 
ingressar na vida do indivíduo. Com isso, a liberdade locomoção tornou-se um dos direitos adquiridos. Os indivíduos teriam liberdade para se movimentar dentro do território de forma livre. É evidentemente um direito negativo. Tal direito apresentou uma relevância tão grande que o remédio constitucional mais conhecido, Habeas Corpus, tem o condão de garanti-lo. Bonavides (2010), discorrendo sobre esse conceito, coloca de manifesto que "os direitos da primeira geração ou direitos de liberdade têm por titular o indivíduo, são oponíveis ao Estado (...), são direitos de resistência ou de oposição perante o Estado" (BONAVIDES, 2010, p. 563564). Com isso, observa-se a proteção do indivíduo frente a atuação estatal desmedida.

Todavia, as demandas sociais frente ao Estado provocaram uma nova dimensão de direitos. O Estado saiu de uma posição inerte para uma colocação ativa. Passou a ter obrigatoriedade de elaborar condutas para possibilitar determinadas prerrogativas aos cidadãos. Mendes e Branco (2015) ensinam "os direitos fundamentais contêm, além de uma proibição de intervenção, um postulado de proteção. Nesse sentido, não apenas uma proibição de excesso, mas uma proibição de proteção insuficiente" (MENDES; BRANCO, 2015, p. 631). Por sua vez, Bonavides (2010), também dissertando sobre o tema, salienta a carga valorativa dos direitos de segunda geração que "passaram a compreender, além daquelas garantias, também critérios objetivos de valores, bem como princípios básicos que animam a lei maior" (BONAVIDES, 2010, p. 568). Todo arcabouço constitucional passa pela avaliação dos direitos de segunda geração. É vedado o olvido deles na interpretação da $C R / 88$. De modo que tanto os direitos de primeira e segunda dimensão estão incluídos no rol de direitos fundamentais.

Os direitos fundamentais sociais estão elencados no art. 60 da $\mathrm{CR} / 88$, sendo que tal dispositivo foi alterado no dia 15 de setembro de 2015 para incluir o direito fundamental social ao transporte. A Proposta de Emenda à Constituição (PEC) foi apresentada no ano de 2011, pela Deputada Luiza Erundina, ex-prefeita da cidade de São Paulo. A fundamentação da proposição foi:

Vetor de desenvolvimento relacionado à produtividade e à qualidade de vida da população, sobretudo do contingente urbano, o transporte destaca-se na sociedade moderna pela relação com a mobilidade das pessoas, a oferta e o acesso aos bens e serviços. Como é de amplo conhecimento, a economia de qualquer país fundamenta-se na produção e no consumo de bens e serviços, como também no deslocamento das pessoas, ações que são mediadas pelo transporte (ERUNDINA, 2011, p. 02).

Segundo a proposição, a inclusão do transporte será um promotor do desenvolvimento nacional, uma vez que obriga o Poder Público a implementação de políticas públicas para possibilitar e facilitar o acesso, a movimentação das pessoas, bens e serviços. O relator na 
Comissão de Constituição e Justiça e de Cidadania atrelou o direito ao transporte a dignidade da pessoa humana, uma vez que a falta de transporte, inviabilizaria o acesso. O relatório diz: "o direito ao transporte é chamado de direito-meio porque ele influencia e condiciona o acesso aos demais direitos, se constituindo em um elemento de vital importância para assegurar as condições necessárias para uma vida digna" (BRASIL, 2013, p. 02). Esse ponto pode ser reafirmado à luz do texto de Araújo e Maia, uma vez que "todas as pessoas têm o direito de participar da vida em sociedade, de conviver com as outras pessoas e de adequadamente desenvolverem suas atividades quotidianas, plenamente incluídas na comunidade em que vive" (ARAÚJO; MAIA, 2016, p. 227). O direito ao transporte é um dos métodos para a inclusão dos indivíduos na vida comunitária. No momento que não é fornecido de forma plena, determinados segmentos da sociedade podem ser prejudicados. Além disso, os autores reafirmam a ligação íntima entre o transporte e a dignidade da pessoa humana (ARAÚJO; MAIA, 2016, p. 227).

É evidente que o desenvolvimento normativo proporcionou esse direito para a população. Tal prerrogativa vem possibilitar um desenvolvimento nacional, algo necessário tendo em vista o paradigma do desenvolvimento sustentável, assim como garantir o acesso físico aos demais direitos, conforme a posição do relator da PEC.

\section{ATUAÇÃO EXECUTIVA DO PODER JUDICIÁRIO}

A separação dos poderes é peça fundamental dentro do constitucionalismo brasileiro, sendo que ele está descrito no art. 2ํ da CR/88 e é cláusula pétrea, em conformidade com o art. $60 \S 4$ o, inciso III, da CR/88. Junto com as gerações de direitos, a separação de poderes foi construída dentro da evolução do estado absolutista para o estado democrático de direito, conforme Zanin (2008, p. 173-177).

Normalmente os poderes são repartidos entre três instituições distintas, independestes e harmônicas. O Poder Legislativo tem como funções típicas a fiscalização e a legislação. O Poder Executivo tem a função executiva (administrativa) e o Poder Judiciário julga. Ocorre que os poderes exercerão atipicamente as funções de outros poderes, trata-se de exceção à separação de poderes. Expõe Zanin (2008) sobre essa atuação delimitada do Poder Judiciário, "coube a tarefa de verificar a compatibilidade da produção do Legislativo e do Executivo perante as diretrizes constitucionais. Para isso ganhou instrumentos de controle de constitucionalidade" (ZANIN, 2008, p. 178). Contudo, esses instrumentos devem ser 
interpretados dentro de uma ordem constituída, salienta Martins (2011) que "o equilíbrio, a harmonia e a independência dos poderes estão rigorosamente disciplinados pelo legislador supremo, o que permite à sociedade brasileira usufruir, num Estado Democrático de Direito, da certeza e da segurança do Direito" (MARTINS, 2011, p. 27). A atuação dos poderes deve, portanto, observar rigorosamente o texto constitucional brasileiro.

A CR/88 no art. 5o, inciso XXXV, informa: "a lei não excluirá da apreciação do Poder Judiciário lesão ou ameaça a direito" (BRASIL, 1988). Esse princípio é base do Estado Democrático de Direito, uma vez que invoca um terceiro desinteressado para promover o processo que busca um resultado. Nesse ínterim, tanto a possibilidade de participação como o respeito ao direito são garantidos pela norma.

Contudo, a doutrina tem alertado para o fenômeno da judicialização de políticas públicas. Barroso (2012) ensina:

Judicialização significa que algumas questões de larga repercussão política ou social estão sendo decididas por órgãos do Poder Judiciário, e não pelas instâncias políticas tradicionais: o Congresso Nacional e o Poder Executivo - em cujo âmbito se encontram o Presidente da República, seus ministérios e a administração pública em geral. Como intuitivo, a judicialização envolve uma transferência de poder para juízes e tribunais, com alterações significativas na linguagem, na argumentação e no modo de participação da sociedade. O fenômeno tem causas múltiplas. Algumas delas expressam uma tendência mundial; outras estão diretamente relacionadas ao modelo institucional brasileiro (BARROSO, 2012, p. 24).

Nesse ínterim, a judicialização da política pode ser conceituada como "a ampliação dos instrumentos judiciais, em que o Judiciário passa a ser visto como uma nova arena pública, que propicia a formação da opinião e uma interpelação direta de indivíduos, de grupos sociais e até de partidos à agenda das instituições políticas" (VIANNA, 1999, p. 22-23).

Por sua vez, Sousa e Gomes (2015) a diferenciam de ativismo judicial, porque:

De forma genérica, a expressão ativismo judicial, vem sendo utilizada pelos Tribunais Superiores, não apenas como uma técnica de controle de constitucionalidade, mas de hermenêutica constitucional, a partir de uma interpretação conforme a Constituição, na interpretação de cláusulas constitucionais abertas, especialmente para sindicar as omissões legislativas, com evidente alargamento de sua competência institucional (SOUSA; GOMES, 2015, p. 48-49).

No caso estudado, o direito ao transporte é de responsabilidade do Poder Executivo, tendo em vista o pacto de poderes. Esse deverá promover políticas públicas capazes de proporcionar o transporte das populações. Quando se utiliza a doutrina de Barroso (2012), 
verifica-se a possibilidade de o Poder Judiciário implementar tal direito. Isso é considerado pelo Ministro do Supremo Tribunal Federal (STF) uma judicialização das políticas públicas.

Barroso (2012) enumera três razões para a massificação desse fenômeno, a saber, a redemocratização brasileira, abrangência da constituição e o sistema de controle de constitucionalidade brasileiros (BARROSO, 2012, p. 24). Esses aspectos decorrem das escolhas políticas do povo brasileiro, que escolheu a democracia inclusiva em resposta ao Regime Militar, além de preferir a constitucionalização de diversas matérias com o intuito de fornecer segurança ao instituto. Sobre a interpretação constitucional, inclusiva a demostrada por Barroso (2012), como característica da CR/88, leciona Torres (2011) que:

A defesa da Constituição implica, assim, a atribuição de direitos às minorias, àqueles que não conseguem reconhecimento de seus direitos por meio da representação política, haja vista que, na contemporaneidade, a democracia, a soberania popular, não equivale mais ao governo de uma maioria, a qual poderia até mesmo aniquilar os opositores. Esta é justamente a grande contribuição do constitucionalismo à democracia, pois o que temos então é o reconhecimento de uma igualdade na diferença, de um governo de todos, minorias ou maiorias, sendo todos cidadãos com direitos constitucionalmente garantidos (TORRES, 2011, p. 193).

A posição da autora (2011) ressalta a necessidade de sopesar o caractere democrático na interpretação constitucional, sendo que a atuação do Poder Judiciário será um modo de proteger as minorias, que não possuem representação dentro do Poder Legislativo, mas têm direitos fundamentais como os grupos majoritários (atuação contra majoritária). Tal posicionamento também se extrai do escólio de Barroso (2012), bem como a impossibilidade de negar acesso aos direitos fundamentais dos indivíduos, com fundamento na separação de poderes.

\section{DESENVOLVIMENTO SUSTENTÁVEL}

O desenvolvimento sustentável se apresenta como novo paradigma de atuação estatal. Este deverá respeitar as dimensões da locução ambiental sob pena de ferir à CR/88. Os pilares clássicos e os modernos estão inseridos no texto constitucional de forma dispersa. A Lei de Mobilidade Urbana ${ }^{5}$ menciona o termo explicitamente, informando da necessidade de observância na promoção de atos relacionados ao direito de locomoção e transporte.

\footnotetext{
${ }^{5}$ Lei no $12.587 / 2012$ (Lei de Mobilidade Urbana) - Institui as diretrizes da Política Nacional de Mobilidade Urbana; revoga dispositivos dos Decretos-Leis nos 3.326, de 3 de junho de 1941, e 5.405, de 13 de abril de 1943, da Consolidação das Leis do Trabalho (CLT), aprovada pelo Decreto-Lei no 5.452, de 10 de maio
} 


\section{Concepção clássica}

A concepção clássica do termo agrega as dimensões econômicas, sociais e ambientais, sendo que a tomada de decisão do ator responsável deve observância a essas dimensões. Caso o ator tome a decisão com base apenas no argumento econômico, não estará configurada uma interpretação sustentável da decisão.

A dimensão econômica é informadora da contínua produção de riquezas, ou seja, a produção constante de algum bem ou serviço. Tal dimensão sempre fora privilegiada nas decisões sócio-políticas, mas o desenvolvimento do campo ambiental permitiu essa mudança paradigmática. A dimensão econômica permaneceu com um peso grande nas decisões, contudo não deverá ser único ou principal. Cenci e Schonardie (2015) salientam como deve ser conduzida esta dimensão econômica da sustentabilidade: "o desenvolvimento progressivo, assim como o progresso econômico, deve atender as necessidades humanas de emprego, alimentação, energia, água e saneamento, relacionados aos chamados direitos básicos da população" (CENCI; SCHONARDIE, 2015, p. 169). Caso a condução seja baseada exclusivamente no pilar econômico, haverá a possibilidade de aumentarem as desigualdades sociais, gerando mais exclusão (CENCl; SCHONARDIE, 2015, p. 172) ${ }^{6}$.

A falta de transporte público de uma região pode ser considerada uma forma de exclusão social, uma vez que impede integrantes de uma comunidade de circularem junto às demais, criando verdadeiros guetos sociais. Sobre o tema Marcelo Gomes Ribeiro (2015) disserta:

A noção de periferia passou a ganhar conotação relevante na sociedade brasileira e se construiu socialmente, sobretudo, em decorrência do processo de urbanização ocorrida no país, que manifestava a diferença das condições sociais das pessoas que não conseguiam moradia nas proximidades do local de trabalho, tendo que buscar alternativas em bairros mais distantes do centro da cidade ou mesmo em outros municípios das regiões metropolitanas. Essas condições sociais eram manifestadas pela carência de infraestrutura urbana que se realizavam, em grande medida, em loteamentos clandestinos, distantes do local de trabalho (RIBEIRO, M. G., 2015, p. 917).

Observa-se que a periferia é o resultado da exclusão social, uma vez que a população sem acesso a renda mais alta, terá que se locomover para regiões distantes do trabalho ${ }^{7}$. Isso demonstra a necessidade de uma rede de transporte eficiente, efetiva e eficaz, uma vez que

de 1943, e das Leis nos 5.917, de 10 de setembro de 1973, e 6.261, de 14 de novembro de 1975; e dá outras providências (BRASIL, 2012).

${ }^{6}$ Em sentido equivalente e analisando um caso concreto, BIZAWU; GOMES, 2016, p. 18-21.

${ }^{7}$ Nesse mesmo sentido Rojas (2017). 
populações mais vulneráveis necessitam de políticas públicas mais específicas. Caso o transporte seja deficitário, poderá alargar a desigualdade social já existente.

A dimensão social, via de regra, é entendida como a dimensão responsável por combater a desigualdade social. Segundo Almeida e Araújo (2013) a função desse pilar "é construir uma civilização com maior equidade na distribuição de renda e de bens, de modo a reduzir o abismo entre os padrões de vida dos ricos e dos pobres" (ALMEIDA; ARAÚJO, 2013, p. 28). Esse abismo pode ser entendido de diversas formas, como a diferença de renda dos integrantes da nação, a possibilidade de apenas alguns conseguirem acessarem serviços públicos, entre outros. A CR/88 elenca como objetivo a redução das desigualdades sociais e regionais, um dos modos de concluir esse objetivo é propiciar uma circulação de pessoas e possibilitar que os excluídos acessem serviços públicos.

A dimensão ambiental foi a responsável pela criação do termo. A mudança provocada pela Estocolmo 1972 e os encontros posteriores, obrigaram essa nova forma de pensar o mundo. Nota-se que esse pilar tem sido utilizado de forma subsidiária, sendo que deveria estar na vanguarda das decisões políticas. Nesse sentido:

é possível afirmar que foram os fatores econômicos e tecnológicos relacionados com o modo de produção e desenvolvimento que influenciaram a forma da cidade xadrez, haja vista que esta modalidade de planejamento urbano tem a característica principal de, como já destacado anteriormente, facilidade de implantação, comercialização e expansão, enquanto que os aspectos naturais tinham uma importância secundária na história de organização dos núcleos urbanos com modelo xadrez (CATÃO, 2015, p. 126).

Ocorre que tais pilares não seriam suficientes para enfrentar o dilema proposto pelo trabalho, assim serão utilizadas novas dimensões que foram tratadas em trabalhos posteriores.

\section{Novas dimensões}

A dimensão espacial é conceituada por Almeida e Araújo (2013) como:

Deve ser dirigida para a obtenção de uma configuração rural-urbana mais equilibrada é uma melhor distribuição territorial de assentamentos urbanos e atividades econômicas, reduzindo a concentração excessiva nas áreas metropolitanas e freando a destruição de ecossistemas frágeis, mas de importância vital através de processos de colonização sem controle (ALMEIDA; ARAÚJO, 2013, p. 29).

Será necessário a observância de critérios sustentáveis para proceder ao aumento das estruturas físicas das cidades. Pode-se citar como esses critérios a necessidade de existência de áreas verdes no interior das cidades, para funcionar como locais de proteção ambiental, mas 
também como espaço de lazer e educação dos residentes e visitantes das cidades. Os parques naturais municipais ${ }^{8}$ previstos no art. $11, \S 4$, da Lei $n^{\circ} 9.985 / 00$ têm essa função. Também é necessária uma construção ordenada de locais de acesso a serviços públicos, não é recomendável uma concentração de serviços em uma área da cidade, tendo em vista a dificuldade de deslocamento entre as regiões. A noção de distribuição de serviços na cidade deve buscar a descentralização e a facilitação do acesso. A ideia de conjugar espaços vazios com as construções também é abstraída desse pilar da locução. No momento de empreender novas construções devem ser observados espaços mínimos e a criação de locais onde não é possível a construção de edifícios. Isso tem a função de possibilitar a circulação do ar, além de evitar uma poluição visual. Esse ponto pode ser utilizado como fator de exclusão. Todavia, deve ser implementado junto com políticas públicas de transporte capazes de transportar um grande número de pessoas pelas distâncias da cidade. Além disso, o aumento espacial da área urbana resulta em um pressionamento das áreas rurais, pois "o crescimento horizontal é definido pelo perímetro da cidade com sua planta urbana, que vai se desdobrando com novos loteamentos ou ações que resultam na incorporação da terra rural à sua área" (CATÃO, 2015, p. 110). Caso não seja observada a referida dimensão pela administração pública, pode ocorrer a destruição das comunidades tradicionais.

A dimensão ética, segundo Freitas (2011, p. 57), trata do dever de fraternidade dentro da espécie e no relacionamento com as demais. O indivíduo deve ser integrado à comunidade, esta à sociedade e esta à universalidade. O dever fraterno deve preponderar nas condutas sociais, impedindo ações puramente egoísticas e que visem o mal-estar dos demais. Araújo e Maia (2016) informam da imprescindibilidade da "necessária a criação de condições para que todos possam efetivamente ser incluídos na sociedade" (ARAÚJO; MAIA, 2016, p. 226). Não é possível construir uma sociedade com base na exclusão de determinados setores sociais.

Outro pilar trabalhado é a noção cultural. O relacionamento da comunidade entre si, é necessário para garantir um desenvolvimento sustentável. Deve-se proteger uma comunidade para garantir os laços culturais pré-existentes. Segundo Froehlich (2014) "ações por meio das quais as comunidades manifestam sua identidade e cultivam tradições de geração em geração"

\footnotetext{
${ }^{8}$ Art. 11 da Lei $n^{\circ}$ 9.985. O Parque Nacional tem como objetivo básico a preservação de ecossistemas naturais de grande relevância ecológica e beleza cênica, possibilitando a realização de pesquisas científicas e o desenvolvimento de atividades de educação e interpretação ambiental, de recreação em contato com a natureza e de turismo ecológico.

[...] § 40 As unidades dessa categoria, quando criadas pelo Estado ou Município, serão denominadas, respectivamente, Parque Estadual e Parque Natural Municipal (BRASIL, 2000, grifos próprios).
} 
(FROEHLICH, 2014, p. 160). A ação estatal deve observar a existências de tradições das sociedades e protegê-las.

Tendo em vista esses pilares informadores do desenvolvimento sustentável é possível responder o problema proposto.

\section{PODER JUDICIÁRIO E O TRANSPORTE PÚBLICO}

Conforme dito anteriormente, o poder que na separação de poderes tem a competência principal de promover políticas públicas é o Poder Executivo, a ele competindo a implementação da política de transporte urbano. O ente responsável para tal conduta é o municipal, tendo em vista o interesse local preponderante. Caberá ao Chefe do Executivo municipal, no caso brasileiro, o Prefeito $^{9}$, promover as diligências necessárias para implementação do direito fundamental ao transporte. Ocorre que o volume de trabalho de um Prefeito é muito grande e assim acaba delegando aos auxiliares. Contudo, no presente trabalho será utilizada a figura do Prefeito, tendo em vista a outorga constitucional.

A Lei no 12.587/12 no art. 5o informa alguns princípios informadores da tomada de decisão do responsável sobre o tema transporte. Importante ressaltar que tal diploma normativo visa regular a situação da mobilidade urbana no Brasil. Foi constituído a Política Nacional de Mobilidade Urbana ${ }^{10}$ e o Sistema Nacional de Mobilidade Urbana ${ }^{11}$. Os princípios estão arrolados no art. 5으 da Lei no 12.587/12:

Art. 5o da Lei no 12.587/12. A Política Nacional de Mobilidade Urbana está fundamentada nos seguintes princípios:

I - acessibilidade universal; || - desenvolvimento sustentável das cidades, nas dimensões socioeconômicas e ambientais; III - equidade no acesso dos cidadãos ao transporte público coletivo; IV - eficiência, eficácia e

\footnotetext{
${ }^{9}$ Art. 30 da CR/88. Compete aos Municípios:

I - legislar sobre assuntos de interesse local; [...] (BRASIL, 1988).

10 Art. $1^{\circ}$ da Lei $n^{\circ} 12.597 / 12$. A Política Nacional de Mobilidade Urbana é instrumento da política de desenvolvimento urbano de que tratam o inciso XX do art. 21 e o art. 182 da Constituição Federal, objetivando a integração entre os diferentes modos de transporte e a melhoria da acessibilidade e mobilidade das pessoas e cargas no território do Município.

Parágrafo único. A Política Nacional a que se refere o caput deve atender ao previsto no inciso VII do art. 20 e no § 20 do art. 40 da Lei no 10.257, de 10 de julho de 2001 (Estatuto da Cidade) (BRASIL, 2012).

Art. 2o da Lei $n^{\circ} 12.597 / 12$. A Política Nacional de Mobilidade Urbana tem por objetivo contribuir para o acesso universal à cidade, o fomento e a concretização das condições que contribuam para a efetivação dos princípios, objetivos e diretrizes da política de desenvolvimento urbano, por meio do planejamento e da gestão democrática do Sistema Nacional de Mobilidade Urbana (BRASIL, 2012).

${ }^{11}$ Art. 3o da Lei $n^{\circ}$ 12.597/12. O Sistema Nacional de Mobilidade Urbana é o conjunto organizado e coordenado dos modos de transporte, de serviços e de infraestruturas que garante os deslocamentos de pessoas e cargas no território do Município (BRASIL, 2012).
} 
efetividade na prestação dos serviços de transporte urbano; $V$ - gestão democrática e controle social do planejamento e avaliação da Política Nacional de Mobilidade Urbana; VI - segurança nos deslocamentos das pessoas; VII - justa distribuição dos benefícios e ônus decorrentes do uso dos diferentes modos e serviços; VIII - equidade no uso do espaço público de circulação, vias e logradouros; e IX - eficiência, eficácia e efetividade na circulação urbana (BRASIL, 2012).

O primeiro princípio é o acesso universal. Este possivelmente agrega dois pilares do desenvolvimento sustentável: o pilar social e o espacial. Tendo em vista que o Brasil é um Estado Democrático de Direito e uma República, não é possível estabelecer diferenças entre os cidadãos, salvo os estabelecidos na $\mathrm{CR} / 88$. Assim toda política pública deve ser voltada para universalização, o que não significa que todos irão utilizar dela e sim os que quiserem. Cita-se a título de exemplo o Sistema Único de Saúde (SUS), do qual todos são destinatários, mas o indivíduo poderá por livre iniciativa procurar por um atendimento particular. Desse modo, deve ser a política de transporte, todos os indivíduos deverão ter acesso aos serviços, mas poderão, na sua liberdade de consciência, escolher outro meio de transporte que não seja o público. Contudo, a possibilidade de escolha do indivíduo não poderá servir de pretexto para omissão estatal na promoção desses serviços debatidos. Esse princípio também possibilita um intercâmbio de concidadãos, uma vez que proporciona a todos o acesso ao mesmo meio de transporte. Tal princípio apresenta evidentemente um caráter integrador.

O segundo princípio da mobilidade urbana é o desenvolvimento sustentável das cidades nas dimensões já estudadas. Esta lei é uma das poucas a trazer explicitamente a locução. Talvez isso se deva ao pouco tempo de estudo da área. O ator público responsável pela implementação dos serviços deve sempre observar os pilares da locução, já que este agrega diretrizes constitucionais. Sobre o assunto:

A intensa busca por medidas e estratégias que convirjam para a almejada sustentabilidade no ambiente urbano também atinge o sistema de transportes, por meio da busca pela mobilidade urbana sustentável. Inerente a esse conceito está a união das questões sociais, econômicas e ambientais relacionadas ao trânsito, visando proporcionar o acesso dos serviços de transporte de forma eficiente. Para o alcance da mobilidade urbana sustentável, é necessária a observância de dois importantes enfoques: a adequação dos sistemas de transportes no âmbito socioeconômico e o nível de impacto ambiental destes (NASCIMENTO; MARTINS; CHACON, 2013, p. 219).

A questão sustentável perpassa por toda discussão sobre a mobilidade urbana. É impossível pensar no assunto sem a devida interpretação sustentável. Caso isso ocorra, o ator político estará agindo de forma ilegal. Piérola e Almeida (2016) reafirmam a necessidade de uma gestão sustentável pelo administrador público municipal, ante a indispensabilidade do "uso 
racional dos recursos públicos, focando na eficiência das despesas do município e compactuando as demandas sociais, ambientais e econômicas de uma maneira justa e inteligente" (PIÉROLA; ALMEIDA, 2016, p. 32). Caso não sejam respeitados tais critérios, o prefeito estará atuando em desacordo com a CR/88 e com a Lei no $12.587 / 12$. Reis e Venâncio (2016) correlacionam a atuação efetiva do gestor público e a conduta privada com o desenvolvimento sustentável, "impõe-se uma alteração de postura, tanto dos indivíduos, por meio de uma educação ambiental, quanto da administração pública, mediante políticas públicas efetivas, que garantam o bem-estar de todos" (REIS; VENÂNCIO, 2016, p. 1209).

A lei também trata do acesso equitativo dos indivíduos. Este princípio informa que o ator deve levar em consideração as diferenças sociais das pessoas na formulação da política pública. Assim, pessoas de renda mais baixa que moram em lugares mais distantes devem ter tarifas diferenciadas ou modo de cobrança mais benéficos. Idosos que geralmente têm muitos gastos extras em função da idade, além de aposentadorias não condizentes com a realidade, têm gratuidade nas tarifas. Nesse ponto, a lógica é tratar os diferentes de forma diferente para equipará-los aos iguais.

O transporte público urbano deve respeitar os critérios de eficiência, efetividade e eficácia. O mais importante para o presente trabalho é a eficiência, ou seja, o transporte público deve ser guiado para alcançar os objetivos propostos com a menor quantidade de insumos disponíveis. Tal conduta permite um decréscimo das tarifas de transporte, proporcionando uma inclusão maior. Além disso, a utilização racional dos insumos presentes é fundamental para sustentabilidade do modelo existente. De maneira que nas decisões sobre o transporte deve privilegiar-se veículos que tenham melhor custo benefício passageiro/valor, devem ser traçadas rotas que atendam os anseios das comunidades, sem que isso implique em uma viagem demasiadamente longa.

A gestão democrática é ponto medular na política pública de transporte público urbano. A CR/88 recolocou a democracia como peça fundamental do Estado brasileiro, sendo que as políticas públicas devem respeitar o caráter democrático, ou seja, devem proporcionar mecanismos para a participação da comunidade no processo decisório. Portanto, o ator político responsável pela política pública de transporte público urbano deverá ouvir e levar em consideração as demandas da sociedade em geral. Geralmente, o órgão representativo é o conselho municipal de transporte. Neste são consideradas cadeiras para o Estado e Sociedade Civil. O caráter democrático é ponto principal na possibilidade de uma comunidade recorrer ao Poder Judiciário para garantia do direito fundamental social ao transporte, uma vez que garante 
a possibilidade de implementação da política pública. Não se pode olvidar que mesmo no contexto democrático, o argumento técnico-burocrático é essencial para a formulação das condutas estatais. Caso fosse esquecido não seria possível falar em uma interpretação efetivamente sustentável. Nestes termos, concluem Cenci e Schonardie (2015) que "a participação do cidadão na gestão das cidades é fundamental para a construção de cidades sustentáveis em todas as suas dimensões"(CENCl; SCHONARDIE, 2015, p. 180).

A segurança dos usuários e não-usuários do transporte público é imprescindível para a política pública. O Estado deve adotar condutas que coadunam os demais princípios, destacando a eficiência com a segurança dos indivíduos. Não será possível adotar práticas que tenham unicamente o objetivo de rapidez do deslocamento, este deve ter um nível de segurança adequado. Este princípio é decorrente do direito à vida e à integridade física.

O princípio da distribuição dos benefícios e ônus deve ser interpretado à luz do acesso equitativo. Não é possível proceder a uma distribuição de ônus (tarifa) de modo a excluir a população mais pobre, que, via de regra, reside em locais mais distantes dos grandes centros urbanos. Esse ponto deve ser interpretado junto com a nova redação do art. 6 o da $C R / 88^{12}$, que garante o transporte. Com isso, o Município deverá participar com recursos financeiros do custeio do transporte coletivo.

Os dois últimos princípios se referem ao ordenamento racional da circulação dos veículos. Deve ser assegurado uma forma de circulação eficiente, eficaz e efetiva, além de uma distribuição justa entre as modalidades de transporte. Salienta-se que uma modalidade não poderá inviabilizar outra.

O ator político na tomada de decisão sobre o transporte público deverá respeitar os pilares do desenvolvimento sustentável, além dos princípios estabelecidos pela Lei de Mobilidade Urbana.

Como dito anteriormente o responsável por essa decisão é o Prefeito. Caso tome uma decisão que impeça a circulação dos residentes de uma determinada comunidade, caberá a discussão desta decisão em outra arena decisória.

O Estado brasileiro é um Estado Democrático de Direito que possibilita ao indivíduo o acesso ao Poder Judiciário para resolução de conflitos. A própria $\mathrm{CR} / 88$ plenamente tal direito de acesso à jurisdição. É inerente a um Estado de Direito a possibilidade de discussão de uma

12 Art. 6o da CR/88. São direitos sociais a educação, a saúde, a alimentação, o trabalho, a moradia, o transporte, o lazer, a segurança, a previdência social, a proteção à maternidade e à infância, a assistência aos desamparados, na forma desta Constituição (Redação dada pela Emenda Constitucional no 90, de 2015) (BRASIL, 1988) (grifo próprio). 
determinada matéria em uma instância independente. Caso uma lei ordinária proíba tal acesso, sua constitucionalidade poderá (deverá) ser discutida. A própria noção de acessar o Poder Judiciário é a garantia de algum direito frente a uma conduta oposta que tenha a força de macerar tal pretensão jurídica. Nota-se que a conduta oposta pode ser de um ente privado ou ainda do ente estatal. Este poderá realizar condutas que ofendam direitos dos particulares, sejam individuais (sentido estrito ou homogêneo), coletivos ou difusos. Na iminência ou após a conduta estatal de cerceamento de direitos, o particular terá a prerrogativa de rediscutir a questão em uma instância dependente, no caso o Poder Judiciário.

Tal afirmação pode ser objeto de inúmeras críticas. A principal delas é a intromissão de um poder em outro. A CR/88 informa que os poderes são independentes e harmônicos entre si. Desse modo, cada um tem a função típica que, segundo essa corrente, não deveria ser alvo de revisão por outro poder. Neste caso o Poder Executivo não poderia legislar sobre matérias exclusivas do Poder Legislativo. Assim, como este não poderia proceder a novo julgamento de uma decisão já tomada pelo Poder Judiciário. Ocorre que esta interpretação não considera o direito de acesso à jurisdição no Estado Democrático de Direito, interpreta a separação de poderes, algo essencial a uma democracia, tendo em vista a multiplicidade das instâncias decisórias, sem a devida garantia a direitos fundamentais. A interpretação deve ser sistemática.

Tal interpretação sistemática permite afirmar que, caso o Prefeito em suas atribuições não promova uma forma efetiva de acesso ao transporte público de uma determinada comunidade, esta terá a possibilidade de recorrer ao Poder Judiciário para garantir os direitos à liberdade de locomoção ${ }^{13}$ e transporte. Ocorrerá uma mudança no ator político responsável pela implementação da política pública. Mesmo existindo essa mudança de ator político responsável, este deverá observar as dimensões do desenvolvimento sustentável, além dos princípios da Lei de Mobilidade Urbana.

\section{APLICAÇÃO DAS DIMENSÕES DA SUSTENTABILIDAdE E DOS PRINCÍPIOS DE MOBILIDADE À DECISÃO ADMINISTRATIVA}

As linhas de circulação de transporte público coletivo são normalmente delimitadas pelo Prefeito ou este delega para algum auxiliar. Os princípios da Lei de Mobilidade Urbana devem ser considerados nesse desenho.

\footnotetext{
13 Art. 5o, inciso XV, da CR/88. É livre a locomoção no território nacional em tempo de paz, podendo qualquer pessoa, nos termos da lei, nele entrar, permanecer ou dele sair com seus bens [...] (BRASIL, 1988).
} 
Ponto inicial na construção da trajetória de um ônibus é a participação das comunidades no processo. Sobre a necessidade da participação popular no processo de tomada de decisões de interesse local, afirma Reis e Venâncio (2016) que:

A participação popular no planejamento das políticas públicas consagra a observância do cumprimento das funções do Estado em consonância com os interesses de todos os indivíduos, hábil a construir uma sociedade integradora, atenta a todas as peculiaridades de dada localidade, em atenção, ainda, às temporalidades a que está sujeita (REIS; VENÂNCIO, 2016, p. 1218).

As populações deverão ser ouvidas para o conhecimento das demandas sociais. Assim o ator político responsável pela decisão já saberá de antemão a quantidade de pessoas da comunidade que utiliza o transporte público, o horário de uso, o principal destino das pessoas, entre outros. Todas essas informações são necessárias para a tomada de decisão informada do ator político, os conhecimentos adquiridos nesta "fase democrática" fundamentarão decisões futuras. Já são percebidos casos de cidades que alteraram estrutura através de políticas públicas desenvolvidas junto com comunidades, nos termos das lições de Aieta (2016, p. 1641-1642).

Junto com essa "fase democrática", é importante uma interpretação sustentável no que tange ao aspecto espacial. A integração das regiões da cidade, mesmo que afastadas, é ponto crucial. O transporte público deverá promover essa integração e o acesso à cidade de comunidades mais distantes. O planejamento urbano sustentável não poderá ser óbice para essas pessoas. Dessa forma, deve-se promover o debate nessas comunidades distantes para sua inclusão na cidade. Importante salientar a concepção de cidade, que "remete a concentração e a aglomeração de indivíduos dividindo e habitando um mesmo espaço, a ideia de organização de um território onde há uma convivência intensa, relações diárias de trocas, permutas de produtos ou serviços" (CENCl; SCHONARDIE, 2015, p. 172). Com isso, a abordagem deve ultrapassar a questão econômica e o desenvolvimento do interesse local deve ser conduzido de forma holística, tendo em vista a pluralidade e a complexidade do fenômeno. O Direito a cidade, que é "basicamente o direito de que todos os habitantes da cidade dispõem de usufruir plenamente da vida urbana, ou seja, de todos os serviços sociais e vantagens ali oferecidos, bem como o direito de participação ativa na gestão do espaço da cidade" (RIBEIRO, T. F., 2015, p. 1502), deve ser respeitado e utilizado na distribuição das linhas de ônibus.

A noção econômica pode ser um contrapeso ao acesso das comunidades. O transporte público tem custos, em alguns casos muito elevados. O ator político tomará a decisão levando em conta a viabilidade econômica do empreendimento. Caso a linha não tenha um patamar mínimo de ocupação, certamente será extinta. Contudo, essa análise econômica não poderá ser 
única e nem preponderante, deverá ser articulada com as demais dimensões e princípios. Município deverá subsidiar linhas que não possuem uma autonomia financeira, com o intuito de garantir o acesso de determinadas localidades. Caso a decisão se baseie exclusivamente na viabilidade financeira com base nas tarifas, populações de regiões mais afastadas e menores dificilmente teriam acesso à cidade. Outro ponto importante na questão de acesso à cidade e a interpretação sustentável é a necessidade do ator político estabelecer tarifas diferenciadas para determinados públicos. Como dito anteriormente, os idosos já possuem uma tarifa diferenciada, algumas Prefeituras têm estabelecido tarifas menores para estudantes e desempregados. Tais condutas têm o condão de implementar o direito fundamental social ao transporte, todavia não podem inviabilizar a atividade de transporte.

Essa noção de tarifa diferenciada para determinados grupos sociais ou para indivíduos que utilizam mais de um veículo de transporte é uma expressão do pilar social, uma vez que trata os distintos de forma diferente para alcançar a igualdade. Ao se ter em vista essa vulnerabilidade das populações, elas são auxiliadas por condutas do Poder Público, para alcançarem o mesmo acesso a cidade que populações mais abastadas. Importante salientar que muitos casos de zonas de exclusão dos mais carentes foram criadas pelo próprio Estado, porque "em grande parte, esta política de retirada dos mais pobres das áreas centrais foi facilitada por meio do crescente número de leis urbanísticas, que estabeleciam normas bastante restritivas para a habitação nas áreas centrais" (RIBEIRO, T. F., 2015, p. 1500).

A decisão de traçado, criação ou extinção de linhas deve respeitar esses parâmetros estudados. Dessa forma, o responsável (Prefeito) pela decisão acerca de linhas de ônibus deverá observar os critérios discutidos. Caso não sejam respeitadas as dimensões do desenvolvimento sustentável e os princípios da Lei de Mobilidade Urbana, a comunidade poderá recorrer ao Poder Judiciário para uma decisão que respeite tais fundamentos.

A comunidade que se sentir excluída da cidade poderá recorrer ao Poder Judiciário para obter uma nova decisão a qual respeite os caracteres estudados. Como dito anteriormente, tal alternativa garante não apenas o direito ao acesso à jurisdição, mas também promove a própria democracia. 


\section{CONSIDERAÇÕES FINAIS}

Após as considerações desenvolvidas, é possível verificar que a hipótese foi confirmada no sentido de obrigar uma interpretação sustentável e principiológica da elaboração da rota do transporte coletivo urbano.

Ficou evidente a mudança do entendimento do instituto transporte no momento em que foi elencado como direito fundamental social. Se, anteriormente, as administrações poderiam se furtar a implementar políticas públicas da área, agora tal omissão tem o caráter de inconstitucional, especialmente por se tratar de direito que visa garantir o acesso aos demais direitos, configurando-se uma projeção da dignidade da pessoa humana.

Restou superada também a possibilidade do Poder Judiciário exercer a função típica do Poder Executivo. Tal atividade ocorrerá de maneira excepcional e apenas quando provocado. Não será possível a alegação de ingerência de um poder sobre o outro, uma vez que o paradigma democrático e a característica analítica da CR/88 proporcionam a discussão em outra arena decisória. O ator político responsável pela decisão deixará de ser o Poder Executivo e passará a ser o Poder Judiciário. Caso tal mudança fosse vedada, dificilmente o Brasil poderia ser enquadrado em um Estado Democrático de Direito.

Comprovou-se também a necessária ressignificação da locução desenvolvimento sustentável para a questão da mobilidade urbana, uma vez que são de suma importância novas dimensões do termo. Além disso, reafirmou-se a necessária observância do instituto na questão analisada, tendo em vista a menção expressa da lei. Verificou-se, ainda, a indispensável observância dos princípios arrolados no art. 50 da Lei de Mobilidade Urbana no processo de criação de rotas do transporte coletivo urbano.

Ao final, comprovou-se a hipótese aventada na introdução do artigo. O ator político responsável pela decisão sobre a trajetória da linha de transporte público deverá observar as dimensões do desenvolvimento sustentável e as diretrizes da Lei de Mobilidade Urbana. Caso não observe, a instância decisória regular (Poder Executivo), poderá ser alterada via ordem judicial para outra (Poder Judiciário). Tal movimento pode ser considerado um controle judicial da política pública de transporte coletivo urbano. 


\section{REFERÊNCIAS}

AIETA, Vania Siciliano. Cidades inteligentes: uma proposta de inclusão dos cidadãos rumo à ideia de "cidade humana". Revista de Direito da Cidade, Rio de Janeiro, vol. 08, no 4, p. 1622-1643, out./dez. 2016. Disponível em: <http://www.epublicacoes.uerj.br/index.php/rdc/article/view/25427>. Acesso em: 06 abr. 2017.

ALMEIDA, Alessandra Bagno F. R. de; ARAÚJO, Marinella Machado. O direito ao desenvolvimento sustentável e a dimensão simbólica de sua aplicação. In: REZENDE, Élcio Nacur; CARVALHO, Valdênia Geralda de (Orgs.). Direito ambiental e desenvolvimento sustentável: edição comemorativa dos dez anos da Escola Superior Dom Helder Câmara. Belo Horizonte: Escola Superior Dom Helder Câmara ESDHC, 2013, p. 11-51.

ARAUJO, Luiz Alberto David; MAIA, Maurício. A cidade, o dever constitucional de inclusão social e a acessibilidade. Revista de Direito da Cidade, Rio de Janeiro, vol. 08, no 1, p. 225-244, jan./abr. 2016. Disponível em: <http://www.e-publicacoes.uerj.br/index.php/rdc/article/view/19901>. Acesso em: 11 jun. 2016.

BARROSO, Luís Roberto. Judicialização, ativismo judicial, legitimidade democrática. (Syn)thesis, Rio de Janeiro, v. 5, no 1, p. 23- 32, jun. 2012. Disponível em: <http://www.epublicacoes.uerj.br/index.php/synthesis/article/view/7433/5388>. Acesso em: 18 nov. 2015.

BIZAWU, Kiwonghi; GOMES, Magno Federici. Oil exploitation at Virunga park as a threat to the environment and to endangered animal species. Veredas do Direito, Belo Horizonte, v. 13, n. 27, p. 11-29, set./dez. 2016. Disponível em: <http://www.domhelder.edu.br/revista/index.php/veredas/article/view/897>. Acesso em: 14 jan. 2017.

BONAVIDES, Paulo. Curso de direito constitucional. 25. ed. São Paulo: Malheiros, 2010.

BRASIL. Comissão de Constituição e Justiça e de Cidadania. Proposta de Emenda à Constituição $n^{\circ}$ 90, de 2011. Câmara dos Deputados, Brasília, 2013. Disponível em: $<$ http://www2.camara.leg.br/proposicoesWeb/prop_mostrarintegra?codteor=1100086\&filena me=Tramitacao-PEC+90/2011--2013>. Acesso em: 18 nov. 2015.

Constituição da República Federativa do Brasil. Diário Oficial, Brasília, 05 out. 1988.

Disponível

em:

<http://www.planalto.gov.br/ccivil_03/constituicao/constituicaocompilado.htm>. Acesso em: 18 nov. 2015.

Emenda Constitucional n 90, de 15 set. 2015. Dá nova redação ao art. 6 da Constituição Federal, para introduzir o transporte como direito social. Altera a redação do art. 60 da Constituição Federal. Diário Oficial, Brasília, 16 set. 2000. Disponível em: <http://www.planalto.gov.br/ccivil_03/constituicao/Emendas/Emc/emc90.htm>. Acesso em: 18 nov. 2015.

Lei $n^{\circ}$ 9.985, de 18 jul. 2000. Regulamenta o art. 225, § 1으, incisos I, II, III e VII da Constituição Federal, institui o Sistema Nacional de Unidades de Conservação da Natureza e dá outras providências. Diário Oficial, Brasília, 19 jul. 2000. Disponível em: <http://www.planalto.gov.br/ccivil_03/leis/19985.htm>. Acesso em: 18 nov. 2015. 
Lei $n^{0}$ 12.587, de 03 jan. 2012. Institui as diretrizes da Política Nacional de Mobilidade Urbana; revoga dispositivos dos Decretos-Leis nos 3.326, de 3 de junho de 1941, e 5.405, de 13 de abril de 1943, da Consolidação das Leis do Trabalho (CLT), aprovada pelo Decreto-Lei no 5.452 , de 1 으 de maio de 1943, e das Leis nos 5.917, de 10 de setembro de 1973, e 6.261, de 14 de novembro de 1975; e dá outras providências. Diário Oficial, Brasília, 04 jan. 2012. Disponível em: <http://www.planalto.gov.br/ccivil_03/_ato2011-2014/2012/lei/l12587.htm>. Acesso em: 18 nov. 2015.

CATÃO, Marconi. Ó. Civilizações urbanas e teorias da cidade. Revista de Direito da Cidade, Rio de Janeiro, vol. 07, no 1, p. 91-140, jan./abr. 2015. Disponível em: <http://www.epublicacoes.uerj.br/index.php/rdc/article/view/15201>. Acesso em: 11 jun. 2016.

CENCI, Daniel Rubens., SCHONARDIE, Elenise Felzke. Direito à cidade: sustentabilidade e desenvolvimento no meio. Revista de Direito da Cidade, Rio de Janeiro, vol. 07, no 1, p. 166-180, jan./abr. 2015. Disponível em: <http://www.epublicacoes.uerj.br/index.php/rdc/article/view/15203>. Acesso em: 17 jan. 2017.

ERUNDINA, Luiza. Proposta de Emenda à Constituição nº 90, de 2011. Dá nova redação ao art. 6o da Constituição Federal, para introduzir o transporte como direito social. Câmara dos Deputados, Brasília. Disponível em: <http://www2.camara.leg.br/proposicoesWeb/prop_mostrarintegra?codteor=925887\&filenam e=PEC+90/2011>. Acesso em: 18 nov. 2015.

FREITAS, Juarez. Sustentabilidade: direito ao futuro. Belo Horizonte: Fórum, 2011.

FROEHLICH, Cristiane. Sustentabilidade: Dimensões e Métodos de Mensuração de Resultados. Revista de Gestão do Unilasalle, Canoas, v. 3, no. 2, p. 151-168, set. 2014.

MARTINS, Ives Gandra da Silva. O ativismo judicial e a ordem constitucional. Revista Brasileira de Direito Constitucional, São Paulo, no 18, p. 23-38, jul./dez. 2011. Disponível em: <http://www.esdc.com.br/RBDC/RBDC-18/RBDC-18-023-

Artigo_Ives_Gandra_da_Silva_Martins_(O_Ativismo_Judicial_e_a_Ordem_Constitucional).pdf $>$. Acesso em: 06 abr. 2017.

MENDES, Gilmar Ferreira; BRANCO, Paulo Gustavo Gonet. Curso de direito constitucional. 10. ed. São Paulo: Saraiva, 2015.

NASCIMENTO, Diego Coelho; MARTINS, Josefa Cicera Alves; CHACON, Suely Salgueiro. O direito ao transporte coletivo urbano na região metropolitana de Cariri- CE: sustentabilidade, problemáticas e alternativas. Veredas do Direito, Belo Horizonte, v. 10, $n^{\circ} 20$, p. 207-230, jul./dez. 2013.2 Disponível em: <http://www.domhelder.edu.br/revista/index.php/veredas/article/view/360>. Acesso em: 18 nov. 2015.

PIÉROLA, Luís Gregório; ALMEIDA, Paulo Santos de. Cidade sustentável: análise das delimitações de ocupação do solo, novo plano diretor estratégico (lei no 16.050/2014) e minuta participativa do projeto de lei de uso e ocupação do solo 2014 da cidade de São Paulo. Revista de Direito da Cidade, Rio de Janeiro, vol. 08, no 1, p. 29-66, jan./abr. 2016. Disponível em: <http://www.epublicacoes.uerj.br/index.php/rdc/article/view/19809>. Acesso em: 17 jan. 2017. 
REIS, Émilien Vilas Boas; VENÂNCIO, Stephanie Rodrigues. O direito à cidade e a participação popular no planejamento urbano municipal. Revista de Direito da Cidade, Rio de Janeiro, vol. 08, no 4, p. 1205-1230, out./dez. 2016. Disponível em: <http://www.epublicacoes.uerj.br/index.php/rdc/article/view/23060>. Acesso em: 06 abr. 2017.

RIBEIRO, Marcelo Gomes. Território e desigualdades de renda em regiões metropolitanas do Brasil. Dados, Rio de Janeiro, vol. 58, no 4, p. 913-949, out./dez. 2015. Disponível em: $<$ http://www.scielo.br/scielo.php?script=sci_arttext\&pid=S001152582015000400913\&lng=en\&nrm=iso\&tlng=pt>. Acesso em: 18 nov. 2015.

RIBEIRO, Tarcyla Fidalgo. Regiões metropolitanas como instrumento de garantia do direito à cidade nos territórios marginalizados dos aglomerados urbanos. Revista de Direito da Cidade, Rio de Janeiro, vol. 07, no 4. p. 1495-1511, número especial 2015. Disponível em: <http://www.e-publicacoes.uerj.br/index.php/rdc/article/view/20905>. Acesso em: 10 jun. 2016.

ROJAS, Madisson Yojan Carmona. Marco analítico del sistema de autobuses de tránsito rápido BRT. Revista de Direito da Cidade, Rio de Janeiro, vol. 09, no 1, p. 136-162, jan./mar. 2017. Disponível em: <http://www.e-publicacoes.uerj.br/index.php/rdc/article/view/18453>. Acesso em: 06 abr. 2017.

SOUSA, Isabella Saldanha de; GOMES, Magno Federici. Ativismo judicial, democracia e sustentabilidade. Rio de Janeiro: Lumen Juris, 2015.

TORRES, Ana Paula Repolês. A relação entre constitucionalismo e democracia: revisões periódicas e abertura interpretativa. Revista Brasileira de Direito Constitucional, São Paulo, no 18, p. 183-203, jul./dez. 2011. Disponível em: <http://www.esdc.com.br/RBDC/RBDC-18/RBDC18-183-

Artigo_Ana_Paula_Repoles_Torres_(A_relacao_entre_Constitucionalismo_e_Democracia_revis oes_periodicas_e_abertura_interpretativa).pdf>. Acesso em: 05 abr. 2017.

VIANNA, Luiz Werneck. A judicialização da política e das relações sociais no Brasil. Rio de Janeiro: Revan, 1999.

ZANIN, Renata Baptista. A (in)vulnerabilidade dos direitos fundamentais. Revista Brasileira de Direito Constitucional, São Paulo, no 11, p. 171-191, jan./jun. 2008. Disponível em: <http://www.esdc.com.br/RBDC/RBDC-11/RBDC-11-171-Renata_Zanin.pdf>. Acesso em 05 abr. 2017.

Trabalho enviado em 17 de janeiro de 2017.

Aceito em 09 de maio de 2017. 